\title{
RANDOM SET-VALUED FUNCTIONAL DIFFERENTIAL EQUATIONS WITH THE SECOND TYPE HUKUHARA DERIVATIVE
}

\author{
Ho Vu AND LE Si DONG
}

\begin{abstract}
This paper concerns with the initial value problem for random set-valued functional differential equations with the second type Hukuhara derivative (RSFDEs). By using the techniques of successive approximations, the existence and uniqueness of solutions are established. Two kinds of boundedness of the solution are also established. In addition, the problem at least one solution under some conditions is proven and two examples illustrate the results.
\end{abstract}

Mathematics subject classification (2010): 34F05, 34G20, 34A12.

Keywords and phrases: Random set-valued variable, set-valued functional differential equations, successive approximation, at least one solution, second type Hukuhara derivative.

\section{REFERENCES}

[1] T.V. An , N.V. HoA, N.D.PHU, Global existence of solutions for interval-valued integro-differential equations under generalized H-differentiability, Advances in Difference Equations, 217 (2013), 1-16.

[2] U. AbbasR, V. Lupulescu, Set functional differential equations, Comm. Appl. Nonlinear Anal., 18 (2011), 97-110.

[3] B. Ahmad, S. Sivasundaram, The monotone iterative technique for impulsive hybrid set valued integro-differential equations, Nonlinear Anal., 65 (2006), 2260-2276.

[4] B. AhmAD, S. Sivasundaram, Set-valued perturbed hybrid integro-differential equations and stability in terms of two measures, Dynamic Systems Appl., 16 (2007), 299-310.

[5] B. Ahmad, S. Sivasundaram, Stability in terms of two measures for set-valued perturbed impulsive delay differential equations, Commun. Appl. Anal., 12 (2008), 57-68.

[6] F.S. DE BLASI, Semifixed sets of maps in hyperspaces with application to set differential equations, Set-Valued Anal., 14 (2006), 263-272.

[7] B. BEDE, I. J. RudAs, A. L. BENCSIK, First order linear fuzzy differential equation sunder generalized differentiability, Information Science, 177 (2007), 1648-1662.

[8] B. BEDE, Sorin G. GAL, Generalizations of the differentiability of fuzzy-number-valued functions with applications to fuzzy differential equations, Fuzzy Sets and Systems, 151 (2005), 581-599.

[9] F.S. DE Blasi, F. IERVolino, Equazioni differenziali con soluzioni a valore compatto convesso, Boll. Unione Mat. Ital., 4 (1969), 491-501.

[10] T. Gnana Bhaskar, V. Lakshmikantham, J.V. Devi, Nonlinear variation of parameters formula for set differential equations in a metric space, Nonlinear Anal. TMA, 63 (2005), 735-744.

[11] M. Cichoń, H. A.H. S ALem, Set-valued system of fractional differential equations with hysteresis, Applied Mathematics and Computation, 215 (2010), 3824-3829.

[12] Y. Feng, Fuzzy stochastic differential systems, Fuzzy Sets and Systems, 115 (2000), 351-363.

[13] W. FEI, Existence and uniqueness for solutions to fuzzy stochastic differential equations driven by local martingales under the non-Lipschitzian condition, Nonlinear Analysis, 76 (2013), 202-214. 
[14] J. K. Hale, Theory of Functional Differential Equations, Second edition. Applied Mathematical Sciences, Vol. 3, Springer-Verlag, New York-Heidelberg, 1977.

[15] S. Hong, J. LiU, Phase spaces and periodic solutions of set functional dynamic equations with infinite delay, Nonlinear Analysis, 74 (2011), 2966-2984.

[16] O. KaleVA,Fuzzy differential equations, Fuzzy Sets and Systems, 24 (1987), 301-317.

[17] A. Khastan, R. RodRígueZ-LóPeZ, Periodic boundary value problems for first-order linear differential equations with uncertainty under generalized differentiability, Information Sciences, 222 (2013), 544-558.

[18] N.V. HoA, N.D.PHU, Fuzzy functional integro-differential equations under generalized $H$ differentiability, Journal of Intelligent and Fuzzy Systems. (In press), doi 10.3233/IFS-130883.

[19] N.V. HoA, N.D.PHU, On maximal and minimal solutions for Set-valued differential equations with feedback control, J. Abstract and Applied Analysis, (2012). doi:10.1155/2012/816218.

[20] V. Lakshmikantham, T. Gnana Bhaskar, J.V. Devi, Theory of set differential equations in metric spaces, Cambridge Scientific Publisher, UK, 2006.

[21] V. Lakshmikantham, Set differential equations versus fuzzy differential equations, Appl. Math. Comput., 164 (2005), 277-294.

[22] C. Lungan, V. Lupulescu, Random dynamical systems on time scales, Electron. J. Differential Equations, 86 (2012), 1-14.

[23] V. Lupulescu, U. Abbas, Fuzzy delay differential equations, Fuzzy Optim. Decis. Mak., 11 (2012), 99-111.

[24] V. LupUlescu, On a class of fuzzy functional differential equations, Fuzzy Sets and Systems, 160 (2009), 1547-1562.

[25] R. RODRÍGUEZ-LóPEZ, On the existence of solutions to periodic boundary value problems for fuzzy linear differential equations, Fuzzy Sets and Systems, 219 (2013), 1-26.

[26] M.T. MalinowsKi, On random fuzzy differential equations, Fuzzy Sets and Systems, 160 (2009), 3152-3165.

[27] M.T. MALinows KI, Existence theorems for solutions to random fuzzy differential equations, Nonlinear Analysis: Theory, Methods \& Applications, 72 (2010), 1515-1532.

[28] M.T. MALINOWSKI, Random fuzzy differential equations under generalized Lipschitz condition, Nonlinear Analysis: Real World Applications, 13 (2012), 860-881.

[29] M.T. Malinows KI, Interval Cauchy problem with a second type Hukuhara derivative, Information Sciences, 213 (2012), 94-105.

[30] M.T. MALINOWS KI, Second type Hukuhara differentiable solutions to the delay set-valued differential equations, J. Applied Mathematics and Computation, 218 (2012), 9427-9437.

[31] M.T. Malinows KI, Interval differential equations with a second type Hukuhara derivative, Applied Mathematics Letters, 24 (2011), 2118-2123. doi:10.1016/j.aml.2011.06.011.

[32] M.T. MalinowsKi, On set differential equations in Banach spaces - a second type Hukuhara differentiability approach, Applied Mathematics and Computation, 219 (2012), 289-305. doi:10.1016/j.amc.2012.06.019.

[33] M.T. Malinowski, Peano type theorem for random fuzzy initial value problem, Discussiones Mathematicae Differential Inclusions, Control and Optimization, 31 (2011), 5-22. doi:10.7151/dmdico.1125.

[34] M.T. MaLINOws Ki, Itô type stochastic fuzzy differential equations with delay, Systems Control Lett., 61 (2012), 692-701.

[35] M.T. MaLINOws KI, Approximation schemes for fuzzy stochastic integral equations, Applied Mathematics and Computation, 219 (2013), 11278-11290.

[36] M.T. MaLinOwS KI, Strong solutions to stochastic fuzzy differential equations of Itô type, Math. Comput. Modelling, 55 ( 2012), 918-928.

[37] M.T. MaLinows KI, Set-valued stochastic integral equations driven by martingales, Journal of Mathematical Analysis and Applications, 394 (2012), 30-47.

[38] M.T. Malinowski, Some properties of strong solutions to stochastic fuzzy differential equations, Information Sciences, 252 (2013), 62-80.

[39] M.T. Malinows Ki, M. Michta, Fuzzy stochastic integral equations, Dynamic Systems and Applications, 19 (2010), 473-494.

[40] M.T. MALINOWSKI, On a new set-valued stochastic integral with respect to semimartingales and its applications, Journal of Mathematical Analysis and Applications, 408 (2013), 669-680. 
[41] I.Mitoma, Y.QKAZAKi, Ji.ZHANG, Set-valued stochastic differential equations in M-type 2 Banach space, Communications in Stochastic Analysis, 4 (2010), 215-237.

[42] F.A. MCRAE, J.V. DEVI, Impulsive set differential equations with delay, Applicable Anal., 84 (2005), 329-341.

[43] J.J. Nieto, R. Rodríguez-López, Some results on boundary value problems for fuzzy differential equations with functional dependence, Fuzzy Sets and Systems, 230 (2013), 91-118.

[44] A.J. Brandao Lopes Pinto, F.S. De Blasi, F. IERvolino, Uniqueness and existence theorems for differential equations with compact convex valued solutions, Boll. Unione. Mat. Italy, 3 (1970), 47-54.

[45] J.Y. PARK, J.U.JeOng, On random fuzzy functional differential equations, Fuzzy Sets and Systems, 223 (2013), 89-99.

[46] N.D. PhU, L.T.QuAng, T.T. Tung, Stability criteria for set control differential equations, Nonlinear Analysis, 69 (2008), 3715-3721.

[47] L. Stefanini, B. Bede, Generalized Hukuhara differentiability of interval-valued functions and interval differential equations, Nonlin. Anal. TMA, 71 (2009), 1311-1328.

[48] N.N. Tu,T.T. Tung, Stability of set differential equations and applications, Nonlinear Analysis, 71 (2009), 1526-1533.

[49] I.-C.TişE, A fixed point approach to functional-integral set equations, Demon. Math., 43 (2010), $815-826$. 